\title{
Total gossypol and oxidation levels of refined cottonseeds oils and crude peanut oils produced in Burkina Faso
}

\author{
1,2, ${ }^{*}$ Zio, S., ${ }^{1}$ Tarnagda, B., ${ }^{1}$ Zongo, O., ${ }^{1}$ Boro, A., ${ }^{2}$ Elothmani, D., ${ }^{2}$ LE Meurlay, D., \\ ${ }^{2}$ Lancon Verdier, V. and ${ }^{1}$ Savadogo, A. \\ ${ }^{1}$ Laboratoire de Biochimie et d'Immunologie Appliquées, Université Joseph KI-ZERBO, 03 BP 7021 \\ Ouagadougou 03, Burkina Faso \\ ${ }^{2}$ Laboratoire GRAPPE, Ecole Supérieure d'Agricultures, Université Bretagne Loire, SC 1422 GRAPPE, \\ INRAE, Ecole Supérieure d'Agricultures, SFR 4207, QUASAV, 55 rue Rabelais 49100 Angers, France
}

\begin{abstract}
Article history:
Received: 6 June 2021

Received in revised form: 8 July 2021

Accepted: 27 September 2021 Available Online: 31

December 2021
\end{abstract}

Keywords:

Refined oil,

Crude oil,

Cottonseeds,

Peanut,

Gossypol,

Oxidation

DOI:

https://doi.org/10.26656/fr.2017.5(6).357

\begin{abstract}
Edible oils produced and consumed in Burkina Faso often do not meet established standards. The objective of this study was to evaluate the total gossypol level of refined cottonseeds oils and the oxidation state of crude peanut oils and refined cottonseeds oils in Burkina Faso to determine the impact on consumer health. A total of 61 samples including crude peanut oils and refined cottonseeds oils were collected in Ouagadougou, Bobo Dioulasso and surrounding areas. Total Gossypol and $p$-Anisidine value were determined by spectrophotometry. Peroxide value, acid value, soap residual value and mineral oils were determined by chemical methods. Total oxidation (Totox) value was determined by mathematical prediction. Overall, Gossypol total average of cottonseeds oils analyzed in this study was $0.032 \%$. The $p$-Anisidine value average was 1.80 for refined cottonseeds oils and 11.65 for crude peanut oils. The Totox averages were respectively 19.37 and 28.36 for refined cottonseeds and crude peanut oils. The average peroxide values for refined cottonseeds oils and peanut crude oils were 8.52 and $8.33 \mathrm{mEq} \mathrm{O}_{2} / \mathrm{Kg}$, respectively $(p<0.05)$. The average acid values were 0.27 and $1.95 \mathrm{mg} \mathrm{KOH} / \mathrm{g}$ for refined cottonseeds oils and crude peanut oils, respectively $(p<0.05)$. None of the oils showed any mineral oil trace. The average residual soap values were respectively 1.47 and $8.32 \mathrm{ppm}$ for peanut oils and cottonseeds oils $(p<0.05)$. The majority values determined conformed to the Codex Alimentarius standard despite some cases of non-compliance. It is essential to improve the processes of oils production and conservation in order to have quality oils to guarantee the health of the consumer.
\end{abstract}

\section{Introduction}

Vegetable oils are foodstuffs that consist mainly of fatty acid glycerides of exclusively vegetable origin. They may contain small amounts of other lipids such as phosphatides, unsaponifiable constituents and free fatty acids naturally present in the fat or oil (Codex Alimentarius, 1999). Vegetable oils have an indispensable role in the body (Fahy et al., 2005). In addition to their role as energy, structural and functional, vegetable oils are sources of essential fatty acids. These essential fatty acids cannot be synthesized by humans and animals and must therefore be provided by the diet (Lecerf, 2010).

However, recent studies have suggested that diet plays a key role in the development of pathologies such as cancers or neurodegenerative diseases. As a result, consumers are exposed to certain toxic contaminants found in food (Engel et al., 2014). Among the foods concerned; there are lipids. Indeed, lipids are sensitive to oxidation which alters the components of the oil such as vitamins and pigments (Roman, 2012). In addition to oxidation, lipids contain endogenous anti-nutritional factors such as erucic acid, cycloprenic acid, gossypol and exogenous factors including mycotoxins and pesticides. In Burkina Faso, several oilseeds and nuts are processed by agribusinesses. These are cottonseeds, shea nuts, peanuts and sesame (Traoré, 2005). Burkina Faso is a producer of vegetable oils. However, locally produced oils sold in markets are often exposed to conditions that do not all meet the standards established for this purpose (Zio et al., 2020). Bad conservation of these oils leads to 
their oxidation which results in the formation of secondary compounds.

Among endogenous compounds, gossypol is a species-specific secondary metabolite of Gossypium and protects the cotton plant from pests (Zhao et al., 2020). It is a yellow pigment present in free or bound form in all parts of cotton plants. The highest levels are found in the seeds (European Food Safety Authority, 2009). Ruminants tolerate gossypol, but it is toxic to nonruminants (Agarwal et al., 2003) such as humans. As far as oxidation compounds are concerned, volatile aldehydes are secondary oxidation compounds that play a key role as they are responsible for "rancid" flavours. For this reason, the oxidation reaction is often associated with the notion of aldehydes chemical rancidity (Gharby, 2012). There are several factors responsible for this oxidation, including the lipid class, lipid composition, oxygen concentration, light and presence of antioxidants. All of these factors influence the hydroperoxides formation and degradation into secondary oxidation products (Gharby, 2012). Indeed, the primary oxidation products of oils are composed of several unstable compounds. As a result, hydroperoxides are rapidly broken down into free radicals (Villière and Genot, 2006). According to these authors, under the effect of heat or metals, they decompose, giving rise to secondary products. Among the latter, volatile compounds are responsible for the modification of the odour of oxidized products. Another, the peroxide value is used to evaluate oxidation compounds. It is used to assess the hydroperoxides presence in edible oils and provides an overall estimate of the oxidation state (Roman, 2012). As for the $p$-Anisidine value, it is more used to evaluate conjugated aldehydes compounds (Gharby, 2012), primarily 2-alkenals and 2,4-alkadienals generated due to hydroperoxide decomposition (Yang and Boyle, 2016). In addition, total oxidation (Totox) is an indicator of the total oxidation of oils (Myat et al., 2009). One of the consequences of oil oxidation is the formation of potentially toxic oxidation products (Kubow, 1992; Farhoosh and Esmaeilzadeh Kenari, 2009) for consumer health. Chronic ingestion of oxidation products would be the most worrying consequence in nutrition and health terms of lipid oxidation (Riemersma, 2002). It is the same for gossypol, a toxic pigment and the main dye in cottonseeds oils. Also, the presence of soap traces in some edible oils has been reported (Zio et al., 2016). The presence of toxic compounds requires the refining of edible oils. The purpose of refining is therefore to maintain or improve the organoleptic characteristics, nutritional characteristics and stability of oils. For this purpose, refining uses several steps to eliminate unwanted compounds and contaminants potentially present in the raw materials, while controlling the formation of new undesirable compounds (Evrard et al., 2007). In Burkina Faso, the production of edible oils is dominated by a myriad of informal craft enterprises, which can contribute to low-quality edible oil (SongNaba, 2016). Hence, the objective of this study is to assess the total gossypol level of cottonseeds oils, soap traces, mineral oils presence and the oxidation state of crude peanut oils and cottonseeds oils produced in Burkina Faso and to know their health impact on consumer health.

\section{Materials and methods}

\subsection{Sample collection}

The oil samples collected were crude peanut oils and refined cottonseeds oils. A total of sixty-one (61) samples were collected randomly in $500 \mathrm{~mL}$ amber vials, sealed, coded, transferred to the laboratory and stored for future analysis. The samples were collected from Ouagadougou, Bobo Dioulasso and surrounding areas. The choice of edible oils sampling sites is based on the high density of edible oils factories, the markets and the consumers. Specifically, thirty (30) samples of refined cottonseeds oils including fifteen (15) samples taken in Ouagadougou-Pabré and fifteen (15) samples taken in Bobo Dioulasso were collected. For peanut oils, thirtyone (31) samples including sixteen (16) samples taken in Ouagadougou-Saaba and fifteen (15) samples taken in Bobo Dioulasso were collected.

\subsection{Gossypol level determination}

The spectrophotometric method described by Pons et al. (1951) using $p$-Anisidine (Pons et al., 1951; Paquot et al., 1962; Chamkasem, 1988) was used. This method involves three solutions, hexane-isopropanol (79.4/20.6; $\mathrm{V} / \mathrm{V}), p$-Anisidine solution and the glacial acetic acid solution. The gossypol standard solution was prepared by dissolving $12.5 \mathrm{mg}$ of pure gossypol in the hexaneisopropanol solution and diluting it to $100 \mathrm{~mL}$ with the solvent. Gossypol standard solutions were obtained in six volumetric flasks after dilution of stock solution to 10 $\mathrm{mL}$ with a hexane-isopropanol solution for the calibration curve. The concentrations of these standards solutions ranged from 0.0125 to $0.075 \mathrm{mg} / \mathrm{mL}$. For oil samples, $2 \mathrm{~g}$ were weighed into a $10 \mathrm{~mL}$ volumetric flask and diluted to volume with the hexane-isopropanol. An aliquot of $0.8 \mathrm{~mL}$ of sample solution was pipetted into 10 $\mathrm{mL}$ volumetric flasks and $1.2 \mathrm{~mL}$ acetic acid solution was added and diluted to $10 \mathrm{~mL}$ with the hexaneisopropanol mixture. This is the sample blank. To the other aliquot, $1.2 \mathrm{~mL}$ of $p$-Anisidine solution was added and heated in a water bath at $60^{\circ} \mathrm{C}$ for half an hour. It was removed from the bath, cooled at room temperature and diluted to volume $(10 \mathrm{~mL})$ with the hexane- 
isopropanol mixture. Absorbances were read with a spectrophotometer $\left(\mathrm{mc}^{2} /\right.$ Safas Monaco) at $447 \mathrm{~nm}$ (Pons et al., 1951; Paquot et al., 1962) for $p$-aniaidinogossypol complex (Paquot et al., 1962). Using the absorbance value, the gossypol is determined in the oil sample aliquot by the average of the calibration curve.

\section{3 p-Anisidine determination}

A quantity of $1.5 \mathrm{~g}$ oil was diluted in $25 \mathrm{~mL}$ of 2,2 , 4-trimethylpentane (Iso-octane) and vortexed for a few minutes. The oil solution absorbance $(\mathrm{Ab})$ was measured by spectrophotometry at $350 \mathrm{~nm}$. Then, $5 \mathrm{~mL}$ oil solution was taken from a first tube, and in parallel $5 \mathrm{~mL}$ of control solvent was taken from a second tube. A $1 \mathrm{~mL}$ of a freshly prepared $p$-Anisidine solution $(0.25 \% \mathrm{w} / \mathrm{v})$ in glacial acetic acid was added to each tube. After 10 mins in the dark, the solvent absorbance (As) in the first tube was measured at $350 \mathrm{~nm}$ using a spectrophotometer (Safas Monaco $\mathrm{mc}^{2}$ ). The $p$-Anisidine is given by the following formula :

$p A V=[25 \times(1.2 A s-\mathrm{Ab})] / \mathrm{m}$

Where As $=$ oil solution absorbance after reaction with $p$ Anisidine, $\mathrm{Ab}=$ oil solution absorbance, $\mathrm{PE}=$ test sample mass in $\mathrm{g}$. The measurements were carried out in triplicate for each oil sample (Haq et al., 2017).

\subsection{Total oxidation determination}

Using the peroxide value (PV) and $p$-Anisidine $(p \mathrm{AV})$ value together provides a complete overview of the oils oxidation process. This is total oxidation (Totox). This is a mathematical prediction of oxidation stability and its value is calculated as follows (Medina-Juárez and Gámez-Meza, 2011) :

Totox $=\mathrm{pAV}+2 \mathrm{PV}$

\subsection{Peroxide value determination}

A quantity of $2 \mathrm{~g}$ of oil was weighed into a $250 \mathrm{~mL}$ Erlenmeyer flask. Then, $10 \mathrm{~mL}$ chloroform and $15 \mathrm{~mL}$ acetic acid were added. A volume of $1 \mathrm{~mL}$ potassium iodide was added to this solution. The flask was stoppered, mixed well and placed in the dark for 5 mins. A volume of $75 \mathrm{~mL}$ distilled water was added and the mixture was stirred well. Titration of iodine released by sodium thiosulfate in the presence of starch was performed. A blank was performed under the same conditions as the oil samples (Zio et al., 2016). The peroxide value (PV) was determined by the following formula :

$\mathrm{PV}=(\mathrm{V}-\mathrm{Vo}) \times 1000 / \mathrm{m}$

Where $\mathrm{V}=$ volume of sodium thiosulphate expressed in $\mathrm{mL} ; \mathrm{Vo}=$ volume of sodium thiosulphate of the blank; $\mathrm{m}$ $=$ mass of oil weighed.

\subsection{Acid value determination}

The procedure adopted is as followed: in $250 \mathrm{~mL}$ Erlenmeyer flask, $50 \mathrm{~mL}$ of diethyl ether ethanol mixture was introduced, 15 drops of phenolphthalein were added. The alcoholic $\mathrm{KOH}$ solution was added drop by drop until it turned pink. A test sample of about $10 \mathrm{~g}$ oil was weighed into the above Erlenmeyer flask and dissolved by stirring. The titration of the solution obtained was carried out with the alcoholic potash until it turned pink (Zio et al., 2016). The acid value (AV) in $\mathrm{mg} \mathrm{KOH} / \mathrm{g}$ was determined by the following formula :

$\mathrm{AV}=(\mathrm{V} \times 56.1 \times \mathrm{N}) / \mathrm{m}$

Where $\mathrm{V}=$ potash volume $(\mathrm{mL}), \mathrm{N}=$ potash solution normality, $\mathrm{m}=$ test sample mass $(\mathrm{g})$ and $56.1=\mathrm{KOH}$ molecular weight.

\subsection{Soap traces value determination}

A volume of $50 \mathrm{~mL}$ acetone at $3 \%$ water and three drops of bromophenol blue were put in $250 \mathrm{~mL}$ Erlen. The mixture turned blue after the addition of three drops of soda $(0.01 \mathrm{~N})$. By stirring, it was brought back to light green colouring by the addition of HCL $(0.01 \mathrm{~N})$. A quantity of $40 \mathrm{~g}$ oil was weighed and poured into the contents. After homogenization and settling of the product, the soap presence in oil was noted by the presence of blue colouration of the upper layer. The solution obtained was titrated by HCL $(0.01 \mathrm{~N})$ until it turned yellow (Zio et al., 2016). The residual soap (SV) content in ppm was determined by the following formula :

$\mathrm{SV}=(\mathrm{V} \times 3040) / \mathrm{m}$

Where $\mathrm{V}=\mathrm{HCL}$ volume poured $(\mathrm{mL})$ and $\mathrm{m}=$ mass test sample (g).

\subsection{Mineral oils detection}

In a saponification flask, a volume of $1 \mathrm{~mL}$ of oil was introduced. Then, a volume of $1 \mathrm{~mL}$ potassium hydroxide solution was added and the solution was stirred gently. To this solution was added $25 \mathrm{~mL}$ ethanol. The mixture was boiled under reflux with occasional stirring until complete saponification for about 5 mins. Then $25 \mathrm{~mL}$ of distilled water was added to the soda solution obtained. In the presence of at least $0.5 \%$ mineral oil turbidity develops (Zio et al., 2016).

\subsection{Data analysis}

The statistical analysis was performed using Excel 2013 and SPSS Version 20 software. Data analyses were replicated three times by oil samples. The Fisher test was used to compare the different values obtained at probability thresholds of $p=5 \%$ (significant if $p<0.05$ and non-significant if $p>0.05$ ). Values were expressed in 
average data \pm standard deviation (SD).

\section{Results and discussion}

The gossypol level in refined cottonseeds oils was evaluated. The gossypol levels in cottonseeds oils are shown in Table 1. Gossypol values range from 0.014 to $0.050 \%$ for oils produced in Ouagadougou and Pabré with an average of $0.025 \%$. For cottonseeds oils produced in Bobo Dioulasso, gossypol values range from 0.008 to $0.082 \%$ with an average of $0.039 \%(p<0.05)$. The overall Gossypol average is $0.032 \%$. The oils produced in Bobo Dioulasso have the highest gossypol content. This difference could be due to the oils refining process or cottonseeds origin. The gossypol level in cottonseeds oils should be zero (ARCOP, 2017). Several authors have determined gossypol in cottonseeds oils. This is the case of Chamkasem (1988) who obtained the averages 0.67 and $1.39 \%$ respectively by HPLC and AOCS methods. For cottonseeds oils obtained by screw pressing, they obtained 0.05 and $0.25 \%$ for HPLC and AOCS methods, respectively (Chamkasem, 1988). Other authors obtained values of $2.42 \%$ and $2.84 \%$ using the AOCS and FTIR methods, respectively (Mirghani and Che Man, 2003). The values obtained by these authors are higher than those of our study. This confirms a certain mastery of the refining process. It follows that oil extraction and quantification methods have an impact on the gossypol content because of a slight modification of the gossypol molecular structure during preconditioning. The spectrophotometric method generally has higher contents because it is not specific. As a result, molecules with structures similar to gossypol such as triglycerides interfere and increase the gossypol level (Chamkasem, 1988). Also, the gossypol content in plant tissues varies according to several factors such as cultivar, phenology or plant organ (De la Paz Celorio-Mancera et al., 2011). Finally, high temperatures during plant development and the ripening period decrease gossypol levels while high rainfall after this period has the opposite effect (Diaw et al., 2011). Indeed, gossypol can be used as a male contraceptive reagent (Lopez et al., 2005), anticancer, antibacterial (Zhao et al., 2020), antimalarial compound, and has proapoptotic properties (Karishma et al., 2016). The primary target organ for gossypol toxicity following repeated exposure to lower doses in humans is the testis, which exhibits reduced sperm motility, inhibited spermatogenesis and decreased sperm count (Karishma et al., 2016). In refined cottonseeds oils, total gossypol values range from 0 to $900 \mathrm{mg} / \mathrm{kg}$ dry weight (European Food Safety Authority, 2009). Solvent extraction, mechanical fractionation and membrane separation have been used to remove gossypol (Singh et al., 2015). Treatment of cottonseeds oil with alkali or alkaline salts removes gossypol. Although almost all of the gossypol is removed during refining to prevent the risk of toxicity, a

Table 1. Gossypol level in refined cottonseeds oils

\begin{tabular}{lccc}
\hline City & Sample number & Range (\%) & Mean \pm SD (\%) \\
\hline OP & 15 & $0.014-0.050$ & $0.025 \pm 0.008^{\mathrm{a}}$ \\
BD & 15 & $0.008-0.082$ & $0.039 \pm 0.020^{\mathrm{b}}$ \\
OP and BD & 30 & $0.008-0.082$ & $0.032 \pm 0.017^{\mathrm{c}}$ \\
\hline
\end{tabular}

Values with different superscripts within the same column are significantly different $(\mathrm{p}<0.05)$.

$\mathrm{SD}=$ Standard deviation of triplicate samples. $\mathrm{OP}=$ Ouagadougou - Pabré, BD = Bobo Dioulasso, $\%=$ Percentage ( $\mathrm{g}$ of gossypol/100 $\mathrm{g}$ of oils).

sufficient quantity remains to affect the conservation quality of the oil (Mirghani and Che Man, 2003).

Acid values for cottonseeds oils and peanut oils are shown in Table 2. The acid value of cottonseeds oils ranges from 0.03 to $0.70 \mathrm{mg} \mathrm{KOH} / \mathrm{g}$. Apart from a few samples, the majority of acid values of cottonseeds oils comply with the Codex Alimentarius standard, which is less than $0.60 \mathrm{mg} \mathrm{KOH} / \mathrm{g}$ for refined vegetable oils (Codex Alimentarius, 1999). Crude peanut oils values range from 0.47 to $4.96 \mathrm{mg} \mathrm{KOH} / \mathrm{g}$. The peanut crude oils values are generally in accordance with the Codex Alimentarius standard which states that the acid value of crude vegetable oils should not exceed $4.0 \mathrm{mg} \mathrm{KOH} / \mathrm{g}$ (Codex Alimentarius, 1999). In general, the averages are 0.27 and $1.95 \mathrm{mg} \mathrm{KOH} / \mathrm{g}$ for refined cottonseeds oils and crude peanut oils, respectively $(p<0.05)$. The acid value

Table 2. Acid and peroxide averages of oils

\begin{tabular}{llcccc}
\hline \multirow{2}{*}{ Oils } & \multirow{2}{*}{ City } & \multicolumn{2}{c}{ Range } & \multicolumn{2}{c}{ Mean \pm SD } \\
\cline { 3 - 6 } & & PV & AV & PV & AV \\
\hline \multirow{2}{*}{ Cottonseeds } & OP & $3.37-24.59$ & $0.11-0.54$ & $9.01 \pm 5.34^{\mathrm{a}}$ & $0.28 \pm 0.12^{\mathrm{e}}$ \\
& BD & $1.99-24.73$ & $0.03-0.70$ & $8.03 \pm 6.45^{\mathrm{b}}$ & $0.26 \pm 0.18^{\mathrm{f}}$ \\
\hline \multirow{2}{*}{ Peanut } & OS & $5.49-15.36$ & $0.47-1.96$ & $11.17 \pm 2.29^{\mathrm{c}}$ & $1.16 \pm 0.48^{\mathrm{g}}$ \\
& BD & $2.87-11.47$ & $1.28-4.96$ & $5.30 \pm 2.19^{\mathrm{c}}$ & $2.80 \pm 1.18^{\mathrm{g}}$ \\
\hline Cottonseeds & OP and BD & $1.99-24.73$ & $0.03-0.70$ & $8.52 \pm 5.84^{\mathrm{d}^{*}}$ & $0.27 \pm 0.15^{\mathrm{h}^{*}}$ \\
\hline Peanut & OS and BD & $2.87-15.36$ & $0.47-4.96$ & $8.33 \pm 3.70^{\mathrm{d}^{*}}$ & $1.95 \pm 1.20^{\mathrm{h}^{*}}$ \\
\hline
\end{tabular}

Values with different superscripts within the same column are significantly different $(p<0.05)$. SD $=\mathrm{Standard}$ deviation of triplicate samples, AV = Acid value, $\mathrm{PV}=$ Peroxide value, $\mathrm{OP}=$ Ouagadougou-Pabré, $\mathrm{BD}=$ Bobo Dioulasso, $\mathrm{OS}=$ Ouagadougou-Saaba.

*OP and $\mathrm{BD}$ vs $\mathrm{OS}$ and $\mathrm{BD}$. 
average of cottonseeds oils in this study is slightly higher than the $0.23 \mathrm{mg} \mathrm{KOH} / \mathrm{g}$ of cottonseeds oils reported by Zio et al. (2016) and the $0.2 \mathrm{mg} \mathrm{KOH} / \mathrm{g}$ obtained by Soumanou et al. (2005) and Koudougou and Dicko (2008). Furthermore, the acid value average of cottonseeds oils is lower than the $0.3 \mathrm{mg} \mathrm{KOH} / \mathrm{g}$ of Koudougou and Dicko (2008) and the $0.77 \mathrm{mg} \mathrm{KOH} / \mathrm{g}$ obtained by Sedeek et al. (2012). For crude peanut oils, the average $1.95 \mathrm{mg} \mathrm{KOH} / \mathrm{g}$ of this study is lower than the values $3.048 \mathrm{mg} \mathrm{KOH} / \mathrm{g}, 4.84 \mathrm{mg} \mathrm{KOH} / \mathrm{g}$ reported by Kandji (2001) and Soumanou et al. (2005), respectively. A high acid value indicates the presence of free fatty acids in oils resulting from hydrolysis. The acid value is an indicator used to evaluate the hydrolysis process of oils (Saguy et al., 1996).

Peroxide values of peanut oils and cottonseeds oils analyzed are recorded in Table 2 . The peroxide values of cottonseeds oils ranged from 1.99 to $24.73 \mathrm{mEq} \mathrm{O} / 2 / \mathrm{Kg}$. Some peroxide values of refined cottonseeds oils are higher than the Codex Alimentarius standard for vegetable oils $(10 \mathrm{mEq} \mathrm{O} / \mathrm{Kg})$ with an overall average in accordance with Codex Alimentarius standard (Codex Alimentarius, 1999). The peroxide values of peanut oils range from 2.87 to $15.36 \mathrm{mEq} \mathrm{O}_{2} / \mathrm{Kg}$. All values for crude peanut oils are in accordance with the Codex Alimentarius standard which should not exceed $15 \mathrm{mEq}$ $\mathrm{O}_{2} / \mathrm{Kg}$ for crude vegetable oils (Codex Alimentarius, 1999). The averages for refined cottonseeds oils and crude peanut oils are 8.52 and $8.33 \mathrm{mEq} \mathrm{O}_{2} / \mathrm{Kg}$, respectively $(p<0.05)$. The average of peanut oils in this study is lower than the average $9.45 \mathrm{mEq} \mathrm{O} 2 / \mathrm{Kg}$ (Myat et al., 2009), $10.16 \mathrm{mEq} \mathrm{O}_{2} / \mathrm{Kg}$ obtained by Zio et al. (2016) and $21.90 \mathrm{mEq} \mathrm{O} \mathrm{O}_{2} / \mathrm{Kg}$ (Kandji, 2001). However, the average of $8.52 \mathrm{mEq} \mathrm{O} / 2 \mathrm{Kg}$ of cottonseeds oils is higher than the average $4.25 \mathrm{mEq} \mathrm{O}_{2} / \mathrm{Kg}$ (Zio et al., 2016), $3.85 \mathrm{mEq} \mathrm{O}_{2} / \mathrm{Kg}$ obtained by Chabiri et al. (2009). On the other hand, the average $8.52 \mathrm{mEq} \mathrm{O} / 2 \mathrm{Kg}$ of cottonseeds oils is lower than the $8.9 \mathrm{mEq} \mathrm{O} / \mathrm{Kg}$ of Koudougou and Dicko (2008). The low values of the different studies compared to our study can be explained by the oil oxidation. A high peroxide value may indicate maximum oxidation with high hydroperoxide concentrations. The peroxide value is widely used to measure the oils and fats oxidative rancidity (Ramadan and Mörsel, 2004). The determination of peroxide value can be used as an oxidation value during the first stage of lipid oxidation because hydroperoxides are the main products of lipid oxidation (Ramadan, 2004). It is therefore a value that allows us to assess the first stages of oil oxidative deterioration (Tchiégang et al., 2004; Marmesat et al., 2009).

The $p$-Anisidine averages of oils are shown in Table 3. The $p$-Anisidine values range from 0.01 to 9.68 for refined cottonseeds oils and 0.04 to 45.14 for peanut oils. The averages are 1.80 and 11.65 for cottonseeds oils and peanut oils, respectively $(p<0.05)$. Cottonseeds oils values are near to the values of 1.66 and 2.03 obtained by Basturk et al. (2007). The values obtained in this study are lower than the 10 units not to be exceeded for vegetable oils. This proves that cottonseeds oils contain a small amount of secondary aldehydes oxidation compounds. The average obtained in this study for peanut oils is higher than the 4.22 obtained by Gan et al. (2005). This could indicate a fairly advanced oils oxidation. The high values for peanut oils could be related to the different oils manufacturing processes but also the different conditions of conservation and sale. To this could be added the frying of the cake (Koura-Koura) (Zio et al., 2020) and probably the exposure of the oil to oxygen. The $p$-Anisidine value is comparable only for the same type of oil because the initial value of the $p$ Anisidine value varies according to the oil source (Guillén and Cabo, 2002). This is the case for polyunsaturated fatty acids rich oils that have a high value even when fresh (Roman, 2012). The $p$-Anisidine value is a more reliable and significant test because it measures secondary oxidation products $(\alpha-$ and $\beta$ alkenals), which are more stable during the frying process (Al-Kahtani, 1991). In terms of the maximum threshold, the $p$-Anisidine value of vegetable oils has no known values. However, several authors have admitted a value of 10 units not to be exceeded (Gan et al., 2005; Casal et al. 2010; Cerretani et al., 2008). According to Plard (2014), the content of conjugated dienals is useful to assess the quality of a highly oxidized oil, case of frying oils. These high values could be due to poor storage conditions, sale and unsuitable containers, exposure to sunlight, air, or even old oil stocks. Also, the by-product frying of (Koura-Koura), cake at uncontrolled temperature and for a long time may be the cause of these high values (Pambou-Tobi, 2015). Finally, the $p$-Anisidine value increases linearly with frying time as a function of temperature (Houhoula et al., 2002). It is a systematic measure in quality control to evaluate the quality of oils (Roman, 2012) and a reliable indicator of oxidative rancidity of lipids (Van der Merwe et al., 2004)

The Totox oxidation values (Totox) are recorded in Table 3. The Totox values for cottonseeds oils range from 4.01 to 52.74 while those for peanut oils range from 5.81 to 67.25 . Overall, the averages are 19.37 and 28.36 for refined cottonseeds oils and crude peanut oils, respectively $(p<0.05)$. The Totox average of 28.36 for this study is higher than the average of 20.46 obtained by Myat et al. (2009). This difference could be related to the frying stage of the cake (Koura-koura), especially for a probably long time. The average 19.37 for cottonseeds 
Table 3. Totox and $\mathrm{p}$-Anisidine averages for cottonseeds oils and peanut oils

\begin{tabular}{llcccc}
\hline \multirow{2}{*}{ Oils } & \multirow{2}{*}{ City } & \multicolumn{2}{c}{ Range } & \multicolumn{2}{c}{ Average and SD } \\
\cline { 3 - 6 } & & $p A V$ & Totox & $p A V$ & Totox \\
\hline \multirow{2}{*}{ Cottonseeds } & OP & $0.36-9.68$ & $8.15-50.10$ & $2.02 \pm 2.29^{\mathrm{a}}$ & $20.06 \pm 10.73^{\mathrm{e}}$ \\
& BD & $0.01-4.11$ & $4.01-52.74$ & $1.58 \pm 1.40^{\mathrm{b}}$ & $18.68 \pm 13.83^{\mathrm{f}}$ \\
\multirow{2}{*}{ Peanut } & OS & $4.47-45.14$ & $15.59-67.25$ & $20.69 \pm 10.78^{\mathrm{c}}$ & $43.09 \pm 12.74^{\mathrm{g}}$ \\
& BD & $0.04-5.52$ & $5.81-25.84$ & $2.01 \pm 1,32^{\mathrm{c}}$ & $12.65 \pm 4.88^{\mathrm{g}}$ \\
Cottonseeds & OP and BD & $0.01-9.68$ & $4.01-52.74$ & $1.80 \pm 1.92^{\mathrm{d}^{*}}$ & $19.37 \pm 12.18^{\mathrm{h}^{*}}$ \\
Peanut & OS and BD & $0.04-45.14$ & $5.81-67.25$ & $11.65 \pm 12.31^{\mathrm{d}^{*}}$ & $28.36 \pm 18.20^{\mathrm{h}^{*}}$ \\
\hline
\end{tabular}

Values with different superscripts within the same column are significantly different $(\mathrm{p}<0.05)$. SD $=\mathrm{Standard}$ deviation of triplicate samples, $\mathrm{pAV}=\mathrm{p}$-Anisidine, $\mathrm{OP}=$ Ouagadougou-Pabré, BD = Bobo Dioulasso, OS = Ouagadougou-Saaba.

*OP and $\mathrm{BD}$ vs OS and BD.

oils is higher than the 7.51 reported by Sedeek et al. (2012). By comparison according to the oil type, it should be noted that the Totox of peanut oils is higher than those of cottonseeds oils because they are used for frying cake (Koura-Koura). A study shows that the Totox values of the oils increase with the frying time. In general, the lower the Totox, the more the oil is stable (Xu et al., 2015). The total oxidation value is a representative value of oxidative deterioration because it takes into account both peroxides and aldehydes (Lolos et al., 1999). It should be noted that the chemical composition of fatty acid is involved in the stability of the oil. In principle, oils rich in polyunsaturated fatty acids (linoleic acid and linolenic acid) are less stable (Sedeek et al., 2012) contrary to the oils rich in monounsaturated fatty acids which are more stable $(\mathrm{Xu}$ et al., 2015). The different results obtained in this study for oils produced in different cities are due to the various oil refining process. Indeed, a study revealed two types of the refining process for peanut oils and three types for cottonseed oils in Ouagadougou and Bobo Dioulasso. The oil refining steps are different in all cases. This variability of oil refining process has a negative impact on the quality of the oil produced in Burkina Faso (Zio et al., 2020). Also, poor storage conditions of the oils may be responsible for the different values obtained in this study.

No peanut oil produced in Ouagadougou-Saaba showed soap traces. Values range from 0 to $37.99 \mathrm{ppm}$ for cottonseeds oils. The averages were 1.47 and 8.32 ppm for peanut oils and cottonseeds oils, respectively $(p<0.05)$. A small proportion of oils had soap traces. The values obtained are below the maximum threshold for vegetable oils which is $50 \mathrm{ppm}$ (Codex Alimentarius, 1999). Also, the average ( $8.32 \mathrm{ppm}$ ) for cottonseeds oils in this study is lower than the value $32.90 \mathrm{ppm}$ and 21.70 ppm reported respectively in 2005 and 2006 by Koudougou and Dicko (2008). The average result in this research is lower than the $14.56 \mathrm{ppm}$ obtained by Zio et al. (2016). The low values could be related to the refining process, in particular, the washing after neutralization that removes residual soaps due to soda. It is the same for peanut oils whose average of 1.47 is below the $13.17 \mathrm{ppm}$ (Zio et al., 2016). The presence of soap traces in crude peanut oils could be related to the addition of salt in the production process. The purpose of this salt is to give a taste to the cake (Koura-Koura) (Zio et al., 2020).

The detection of mineral oil traces in cottonseeds oils and peanut oils from the different cities was negative. Not all cottonseeds oils and peanut oils showed traces of mineral oil. These data are similar to those obtained by Zio et al. (2016) in peanut oils and cottonseeds oils from the city of Ouagadougou. However, authors have detected hydrocarbons in vegetable oils (Neukom et al., 2002). Mineral oils in vegetable oil with values between 30 and $150 \mathrm{mg} / \mathrm{kg}$ in foodstuffs were reported (Lacoste et al., 2009).

\section{Conclusion}

Gossypol has been identified in cottonseeds oils $(0.032 \%)$ at low levels. However, its content in cottonseeds oil should be zero. Also, the determination of different oxidation parameters of cottonseeds oils and peanut oils produced in Ouagadougou, Bobo Dioulasso and surrounding areas has made it possible to assess their oxidation state. Most of the values determined were in compliance with the Codex Alimentarius standard. Most of the oils have not undergone oxidation apart from peanut oils. Peanut oils have high values, particularly $p$ Anisidine (11.65) and Totox value (28.36), demonstrating their advanced level of oxidation. The detection of mineral oil was negative for all oils. For soap residual traces, low levels were detected but below the Codex Alimentarius standard. The refining process for cottonseeds oils needs to be improved to remove gossypol traces. Also, the production and preservation of crude peanut oils require special attention. To avoid oxidation of vegetable oils, it is essential to limit their exposure to oxygen, light, high temperatures and keep them in amber containers under nitrogen if necessary. 
Society, 65(10), 1601-1604. https://doi.org/10.1007/ BF02912562

\section{Conflict of interest}

The authors declare no conflict of interest.

\section{Acknowledgements}

We thank the different producers of cottonseeds oils and peanut oils for their frank collaboration. Also, we express our immeasurable gratitude to all the authors who contributed to the achievement of the study objectives. Finally, we thank the Laboratory GAPPE of High School of Agricultures, France, the National Laboratory of Public Health and the Cooperation Service of the French Embassy in Burkina Faso for their support.

\section{References}

Agarwal, D.K., Singh, P., Chakrabarty, M., Shaikh, A.J. and Gayal, S.G. (2003). Cottonseed oil quality, utilization and processing. CICR Technical Bulletin, 1165(25), 1-16.

Al-Kahtani, H.A. (1991). Survey of quality of used frying oils from restaurants. Journal of the American Oil Chemists Society, 68(11), 857-862. https:// doi.org/10.1007/BF02660602

ARCOP. (2017). Guide d'utilisation des normes de qualité en matière de commande publique au Burkina Faso. Retrieved from ARCOP website: http://www.arcop.bf/telechargement/1686 [In French].

Basturk, A., Javidipour, I. and Boyaci, I.H. (2007). Oxidative stability of natural and chemically interesterified cottonseeds, palm and soybean oils. Journal of Food Lipids, 14(2), 170-188. DOI: 10.1111/j.1745-4522.2007.00078.x

Casal, S., Malheiro, R., Sendas, A., Oliveira, B.P.P. and Pereira, J.A. (2010). Olive oil stability under deepfrying conditions. Food and Chemical Toxicology, 48(10), 2972-979. https://doi.org/10.1016/ j.fct.2010.07.036

Cerretani, L., Salvador, M.D., Bendini, A. and Fregapane, G. (2008). Relationship between sensory evaluation performed by Italian and Spanish official panels and volatile and phenolic profiles of virgin olive oils. Chemosensory Perception, 1(4), 258-267. https://doi.org/10.1007/s12078-008-9031-3

Chabiri, S.A., Hati, S.S., Dimari, G.A. and Ogugbuaja, V.O. (2009). Comparative Quality Assessment of Branded and Unbranded Edible Vegetable Oils in Nigeria. Pacific Journal of Science and Technology, 10(2), 927-934.

Chamkasem, N. (1988). Gossypol analysis in cottonseed oil by HPLC. Journal of the American Oil Chemists'
Codex Alimentarius (1999). Norme pour les huiles végétales portant un nom spécifique. Retrieved from Codex Alimentarius website: https:// inspection.canada.ca/DAM/DAM-food-aliments/ WORKAREA/DAM-food-aliments/text-texte/ codex_food_stand_named_veg_oils_153297505719 3 fra.pdf

De la Paz Celorio-Mancera, M., Ahn, S.J., Vogel, H. and Heckel, D.G. (2011). Transcriptional responses underlying the hormetic and detrimental effects of the plant secondary metabolite gossypol on the generalist herbivore Helicoverpa armigera. BMC Genomics, 12, 575. https://doi.org/10.1186/14712164-12-575

Diaw, M.T., Dieng, A., Mergeai, G. and Hornick, J.L. (2011). Les coproduits de la graine de coton en alimentation du poulet de chair. Annales de Médecine Vétérinaire, 155(2), 61-76. [In French]. https://orbi.uliege.be/ bitstream/2268/125761/1/2011_155_2_02.pdf

Engel, E., Meurillon, M., Planche, C. and Peyret P. (2014). Devenir des contaminants toxiques des aliments dans l'environnement digestif. Innovations Agronomiques, 36, 135-149. [In French]. https:// hal.inrae.fr/hal-02634873/document

European Food Safety Authority (2009). Gossypol as undesirable substance in animal feed: scientific opinion of the panel on contaminants in the food chain. European Food Safety Authority Journal, 7 (1), 908. https://doi.org/10.2903/j.efsa.2009.908

Evrard, J., Pages, X.P.X., Argenson, C. and Morin, O. (2007). Processes for obtaining and nutritional compositions of sunflower, olive and rapeseed oils. Nutrition and Diet Books, 42 (Supplemental 1), 1323. https://doi.org/10.1016/S0007-9960(07)91235-3.

Fahy, E., Subramaniam, S., Brown, H.A., Glass, C.K., Merrill, A.H.J., Murphy, R.C., Raetz, C.R., Russell, D.W., Seyama, Y., Shaw, W., Shimizu, T., Spener, F., Van Meer, G., Van Nieuwenhze, M.S., White, S.H., Witztum, J.L. and Dennis, E.A. (2005). A comprehensive classification system for lipids. Journal of Lipid Research, 46(5), 839-861. https:// doi.org/10.1194/jlr.E400004-JLR200

Farhoosh, R. and Esmaeilzadeh Kenari, R. (2009). Antirancidity effects of sesame and rice bran oils on canola oil during deep frying. Journal of the American Oil Chemists' Society, 86(6), 539-544. https://doi.org/10.1007/s11746-009-1382-7

Gan, H.L., Man, Y.B.C., Tan, C.P., NorAini, I. and Nazimah, S.A.H. (2005). Characterization of vegetable oils by surface acoustic wave sensing electronic nose. Food Chemistry, 89(4), 507-518. 
https://doi.org/10.1016/j.foodchem.2004.03.005

Gharby, S. (2012). Contribution à la valorisation de l'huile d'argane : Influence de l'origine du fruit (terroir, forme) et de la méthode d'extraction sur la composition chimique, les caractéristiques organoleptiques et la stabilité de l'huile d'argane. Morocco: Mohammed V University - Agdal Phd Thesis. [In French]

Guillén, M.D. and Cabo, N. (2002). Fourier transform infrared spectra data versus peroxide and Anisidine values to determine oxidative stability of edible oils. Food Chemistry, 77(4), 503-510. https:// doi.org/10.1016/S0308-8146(01)00371-5

Haq, M., Ahmed, R., Cho, Y.J. and Chun, B.S. (2017). Quality Properties and Bio-potentiality of edible oils from Atlantic Salmon by-products extracted by supercritial carbon dioxide and conventional methods. Waste and Biomass Valorization, 8(6), 1953-1967. https://doi.org/10.1007/s12649-016-9710 $-2$

Houhoula, D.P., Oreopoulou, V. and Tzia, C. (2002). A kinetic study of oil deterioration during frying and a comparison with heating. Journal of the American Oil Chemists Society, 79(2), 133-137. https:// doi.org/10.1007/s11746-002-0447-0

Kandji, N. (2001). Etude de la composition chimique et de la qualité d'huiles végétales artisanales consommées au Sénégal. Senegal: Universite Cheikh Anta Diop, PhD Thesis. [In French]

Karishma, R., Lakshmi Sahithya, U., Suneetha, P., Chinna Babu Naik, V. and Krishna, M.S.R. (2016). Determination of total gossypol and free gossypol content in different varieties of BT and non Bt cotton seed extracts by High Performance Liquid Chromatography (HPLC). Research Journal of Biotechnology, 11(2), 70-74.

Koudougou, K. and Dicko, H.M. (2008). Contrôle qualité et amélioration de la production locale: cas des huiles alimentaires produites au Burkina Faso: In Colloque Alimentation et Santé: risques et enjeux. Retrieved from website: https://www.yumpu.com/fr/ document/read/16830645/telecharger-les-actes-ducolloque-universite-senghor-dalexandrie [In French].

Kubow, S. (1992). Routes of formation and toxic consequences of lipid oxidation products in foods. Free Radical Biology and Medicine, 12(1), 63-81. https://doi.org/10.1016/0891-5849(92)90059-P

Lacoste, F., Joffre, F., Coustille, J.L., Morin, O., Soulet, B., Brenne, E. and Griffon, H. (2010). Détection de contaminants dans les huiles végétales: bilan à fin 2009. Oléagineux Corps gras Lipides, 17(2), 75-80. https://doi.org/10.1051/ocl.2010.0301

Lecerf, J.M. (2010). Acides gras, huiles et risque cardiovasculaire: Une saga. Phytotherapie, 8, 77-83.
[In French]. https://doi.org/10.1007/s10298-0100532-2

Lolos, M., Oreopoulou, V. and Tzia, C. (1999). Oxidative stability of potato chips: Effect of frying oil type, temperature and antioxidants. Journal of the Science of Food and Agriculture, 79(11), 1524-1528. https://doi.org/10.1002/(SICI)1097-0010(199908) 79:11<1524::AID-JSFA401>3.0.CO;2-H

Lopez, L.M., Grimes, D.A. and Schulz, K.F. (2005). Non hormonal drugs for contraception in men: a systematic review. Obstetrical and Gynecological Survey, 60(11), 746-752. https:// doi.org/10.1097/01.ogx.0000182905.71077.13

Marmesat, S., Morales, A., Velasco, J., Ruiz-Méndez, M.V. and Dobarganes, M.C. (2009). Relationship between changes in peroxide value and conjugated dienes during oxidation of sunflower oils with different degree of unsaturation. Grasas y Aceites, 60 (2), 155-160. https://doi.org/10.3989/gya.096908

Medina-Juárez, L.Á. and Gámez-Meza, N. (2011). Effect of refining process and use of natural antioxidants on soybean oil. In Ng, T.-B. (Ed.) Biochemistry, Chemistry and Physiology, p. 435-460. InTech Open E-Book. https://doi.org/10.5772/15826

Mirghani, M.E.S. and Che Man, Y.B. (2003). A new method for determining gossypol in cottonseed oil by FTIR spectroscopy. Journal of the American Oil Chemists' Society, 80(7), 625-628. https:// doi.org/10.1007/s11746-003-0749-2

Myat, M.W., Abdulkarim, S.M., Ghazali, H.M. and Roselina, K. (2009). Physicochemical and sensory characteristics of palm olein and peanut oil blends. Journal of Food, Agriculture and Environment, 7(34), 175-181. https://doi.org/10.5539/jas.v2n4p18

Neukom, H.P., Grob, K., Biedermann, M. and Noti, A. (2002). Food contamination by C20-C50 mineral paraffins from the atmosphere. Atmospheric Environment, 36(30), 4839-4847. https:// doi.org/10.1016/S1352-2310(02)00358-8

Pambou-Tobi, N. (2015). Influence des conditions de friture profonde sur les propriétés physicochimiques de la banane plantain Musa AAB "harton": étude du vieillissement des huiles et modélisation des transferts de matière au cours du procédé. France: University of Lorraine, $\mathrm{PhD}$ Thesis. [In French].

Paquot, C., Mercier, J., Lefort, D., Mathieu, A. and Perron, R. (1962). Les méthodes analytiques des lipides simples. Annales de la nutrition et de l'alimentation, 16, 1-281.

Plard, J. (2014). Apport de la chimiométrie et des plans d'expériences pour l'évaluation de la qualité de l'huile d'olive au cours de différents processus de vieillissement. France: Aix Marseille University, PhD Thesis. [In French]. 
Pons, W.A., Hoffpauir, C.L. and O'Connor, R.T. (1951). Determination of total gossypol pigments in cottonseed oils. Journal of the American Oil Chemists' Society, 28(1), 8-12. https:// doi.org/10.1007/BF02639740

Ramadan, M.F. (2013). Healthy blends of high linoleic sunflower oil with selected cold pressed oils: Functionality, stability and antioxidative characteristics. Industrial Crops and Products, 43 (1), 65-72. https://doi.org/10.1016/ j.indcrop.2012.07.013

Ramadan, M.F. and Mörsel, J.T. (2004). Oxidative stability of black cumin (Nigella sativa L.), coriander (Coriandrum sativum L.) and Niger (Guizotia abyssinica Cass.) crude seed oils upon stripping. European Journal of Lipid Science and Technology, 106(1), 35-43. $\quad$ https://doi.org/10.1002/ ejlt.200300895

Riemersma, R.A. (2002). Analysis and possible significance of oxidized lipids in food. European Journal of Lipid Science and Technology, 104(7), 419-420. https://doi.org/10.1002/1438-9312(200207) 104:7<419::AID-EJLT419>3.0.CO;2-S

Roman, O. (2012). Mesure et prédiction de la réactivité des lipides au cours du chauffage d'huiles végétales à haute température. France: AgroParisTech, PhD Thesis. [In French]

Saguy, I.S., Shani, A., Weinberg, P. and Garti, N. (1996). Utilization of jojoba oil for deep-fat frying of foods. LWT - Food Science and Technology, 29(56), 537-577. https://doi.org/10.1006/fstl.1996.0088

Sedeek, S.M., El-Ghobashy, R.E. and Tawfik, M.F. (2012). Thermal stability of cottonseed oil mixed with jojoba or castor oil during frying process. Journal of Biological and Environmental Sciences, 7 (2), 39-56.

Singh, S., Sharma, S.K. and Kansal, S.K. (2015). Extraction of gossypol from cottonseed. Reviews in Advanced Sciences and Engineering, 4(4), 301-318. https://doi.org/10.1166/rase.2015.1105

Song-Naba, F. (2016). Entreprises informelles de transformation agroalimentaire au Burkina Faso: Entre impératifs sanitaires et réalités économiques. Revue Congolaise de Gestion, 1-2, 125-155. [In French]. https://doi.org/10.3917/rcg.021.0125

Soumanou, M.M., Tchobo, F.P., Edorh, A.P. and Accrombessi, G. (2005). Valorisation des huiles végétales d'origine Béninoise par alcoolyse enzymatique. Oilseeds and Fats Crops and Lipids, 12, 320-325. [In French]. https://doi.org/10.1051/ ocl. 2005.0320

Tchiégang, C., Oum, M.N., Dandjouma, A.A. and Kapseu, C. (2004). Qualité et stabilité de l'huile extraite par pressage des amandes de Ricinodendron heudelotii (Bail.) pendant la conservation à température ambiante. Journal of Food Engineering, 62(1), 69-77. [In French]. https://doi.org/10.1016/ S0260-8774(03)00172-9

Traoré, A.S. (2005). En la biotechnologie, un outil efficace dans la lutte contre la faim et la pauvreté Afrique subsaharienne: cas du Burkina Faso, presented at the Maîtrise des Procédés en vue d'améliorer la qualité et la sécurité des aliments, 811 November 2005. Ouagadougou, Burkina Faso. [In French]

Van Der Merwe, G.H., Du Plessis, L.M. and Taylor J.R.N. (2004). Changes in chemical quality indices during long-term storage of palm-olein oil under heated storage and transport-type conditions. Journal of the Science of Food and Agriculture, 84(1), 52-58. https://doi.org/10.1002/jsfa.1609

Villière, A. and Genot, C. (2006). Approche physicochimique et sensorielle de l'oxydation des lipides en émulsions. Oilseeds and Fats Crops and Lipids, 13, 152-159. [In French]. https://doi.org/10.1051/ ocl.2006.0028

Xu, T.T., Li, J., Fan, Y.W., Zheng, T.W. and Deng, Z.Y. (2015). Comparison of oxidative stability among edible oils under continuous frying conditions. International Journal of Food Properties, 18(7), 1478-1490. doi.org/10.1080/10942912.2014.913181

Yang, X. and Boyle, R.A. (2016). Sensory evaluation of oils/Fats and oil/Fat-based foods. In $\mathrm{Hu}, \mathrm{M}$. and Jacobsen, C. (Eds.) Oxidative stability and shelf life of foods containing oils and fats, p. 157-185. USA: AOCS Press. https://doi.org/10.1016/B978-1-63067056-6.00003-3

Zhao, T., Xie, Q., Li, C., Li C., Mei, L., John, Z. Y., Chen, J. and Zhu, S. (2020). Cotton roots are the major source of gossypol biosynthesis and accumulation. BMC Plant Biology, 20, 88. https:// doi.org/10.1186/s12870-020-2294-9

Zio, S., Savadogo, A., Songre-Ouattara, L.T., Tapsoba, F., Bassole, I.H.N., Zongo, C., Nikiema, F. and Traoré, Y. (2016). Physicochemical quality of artisanal oils produced in Ouagadougou: case of four small companies of cottonseeds oils and crude groundnut oils taken in the markets. Journal of Advanced in Biotechnology, 6(2), 890-900. https:// doi.org/10.24297/jbt.v6i2.4803

Zio, S., Somda, N.S., Hama-Ba, F., Sawadogo, A., Tapsoba, F., Traoré, Y. and Savadogo, A. (2020). Cottonseeds and crude peanuts oils production technology and the edible oils sale conditions in Ouagadougou and Bobo Dioulasso Markets. Journal of Nutrition and Food Security, 5(3), 236-247. https://doi.org/10.18502/jnfs.v5i3.3796 